Volume 1, Issue 1, pp 58-65, January 2021, https://doi.org/10.52098/airdj.202124

ISSN: 2788-9696 Received: 22/2/2021 Revised: 22/2/2021 Accepted: 22/2/2021 Editorial

\title{
Social and Telepresence Robots a future of teaching
}

\author{
Jabar H. Yousif ${ }^{1, *}$ \\ ${ }^{1}$ Faculty of Computing \& Information Technology, University of Sohar, Oman \\ *Corresponding author: Jabar H. Yousif ${ }^{1}$, jyousif@su.edu.om.
}

\begin{abstract}
The robotics industry is advancing at rates faster than ever before. It produces plentiful different types of robots incorporated in other fields like medical, defense, manufacturing, and mining industries. Of course, it is no surprise that the robotics industry managed to make its way to the educational field, and with it came the social and telepresence robots. This paper aims to compare social and telepresence robots in the teaching industry in the near future. Both a literature survey and a comparison segment were produced. It was concluded that the future of educational environments would incorporate both of these technologies since they serve different functions. This is to provide the best experience for as wide of a range of people as possible, wherever they are living and whatever disabilities/ challenges they are experiencing.
\end{abstract}

Keywords: Robotics; Telepresence Robots; Social Robots; teaching methods; Student performance 


\section{Introduction}

The digital age made a splashing entrance onto humans' history, and with it came a plethora of wonderful devices and inventions that have become part of our daily lives. Things like smartphones, robotics and cars, and many others allow us to connect over vast distances and do things that were considered impossible just a few decades ago. One particularly fast-growing field is the robotics industry. According to a recent 2020 IFR report (IFR,2020a), there were 422000 units of robots being used worldwide in the industrial field in 2018 and 373000 units in 2019. Blew way past the predictions that were made in another report by them in 2016 (IFR,2020b). Figure 1 shows the numbers of units of robots adopted in the industrial field. This shows fast-advancing robotics and the rate at which it is being adopted in other industries.

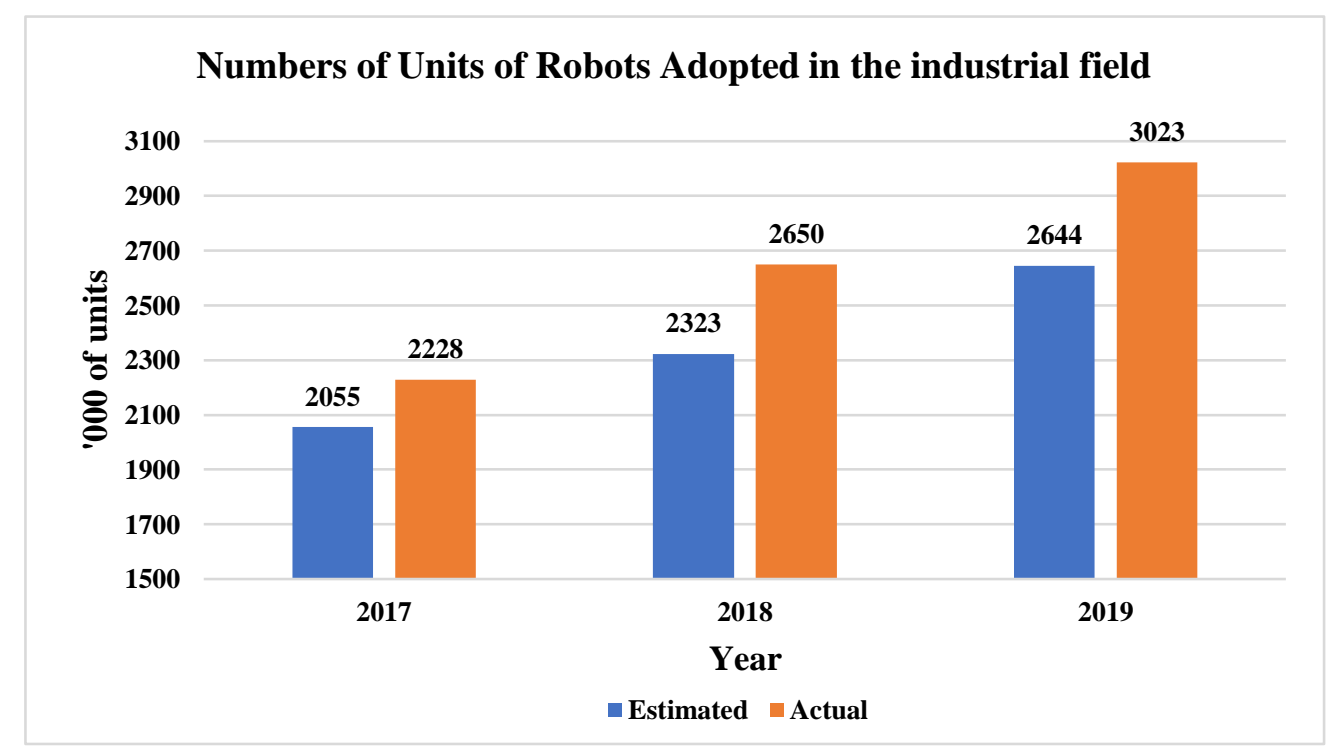

Figure 1: Numbers of Units of Robots Adopted in the industrial field

The robotics industry managed to produce plentiful, relatively low-cost, flexible, and powerful machines that have been incorporated in many other industries, the most notable ones being the medical, defense, manufacturing, and mining industries. Some examples of the improvements that robots have provided in other sectors are increased precision, the medical field, and an increase in safety in the industrial fields due to the robots handling most of the tasks that would either be dangerous or even fatal to humans. Of course, these robotics advancements eventually found their way into the teaching industry in the form of social robots like NAO, KASPAR, Keepon, and telepresence robots like the human-operated robot Kubi, which allows for students/ teachers to "attend" real-life classes without having to be present. No shortage of research papers tests social robots' viability in the classroom, and they have been tested in many different environments. For example, they have been tested on a wide range of ages (preschool, primary, 
secondary, university) and tested with both healthy and special needs children (autism, ADHD, diabetes). Telepresence robots are researched a lot less than their more popular social robot counterparts, but they also have useful roles in education. The primary use allows the user, be it a teacher or a student, to experience an everyday, academic person's life without being present in the teaching facility. This can be of great help to people who have limited mobility, compromised immune systems, or other illnesses that can hamper their ability to attend. This paper aims to compare social and telepresence robots to find out which one is better for use in the teaching industry in the near future.

\section{Literature Survey}

Several research papers discussed and explored the implementation of robots in teaching and learning environment for examining the impact of robots on student performance and engagement.

Saerbeck (Saerbeck et al., 2010) investigated the effect of using a social robot on students learning performance and social skills. It was found that the students showed significant improvements in their performance and were able to more likely to remember what they were taught. Kandlhofer (Kandlhofer, \& Steinbauer, 2014) examined the use of social robots in educating children in the classroom. The paper concluded that the children showed positive improvements in their social and academic performance after being taught by the robot. Pop (Pop et al., 2013) implemented a social robot called "Probo" to educate special needs children. They concluded that the social robot noticeably improved the children's social interaction and they were much more likely to achieve the goal of the task without further assistance. Wang (Wang, et al. 2016) employed a study to gage the usefulness of the social robot Darwin in improving autistic children's emotional interactions with other people. Their results indicated that due to the robot's toy-like, simple nature, it was much easier to teach emotional concepts using the robot rather than a human instructor. The participants also showed worthy development in their overall emotional skills. Chang (Chang et al., 2010) explored the implementation of a collaborative educational environment via the use of a social humanoid robot. They did this by implementing several different teaching "modes", which include the following; storytelling, oral reading, cheerleader, action command, and question and answer. It was concluded that the robot increased engagement during the lessons and the students were more likely to contribute to and learn from the lessons. There are also other papers that discuss the use of social robots ((Jamet et al.,2018); (Alemi et al., 2014); (Conti et al., 2017); (Mubin et al., 2013); (You et al., 2006)). 
Kwon (Kwon et al., 2013) studied the effectiveness of using a telepresence robot in a normal learning environment. They found that while there may have been some slight problems, the telepresence robot almost managed to provide a seamless, in-person like experience for both the teacher and the students being taught. Tanaka (Tanaka et al., 2014) considered the use of telepresence robots instead of regular conferencing apps. They tested this hypothesis with 52 participants to see if the telepresence robots made any improvements in the user experience. Their results concluded that the children were more engaged during the lessons and they were less likely to freeze when asked a question they did not understand. Tanaka (Tanaka et al., 2014) investigated the use of Robovie-R3, a telepresence robot, to help improve the remote learning user experience between students in Australia and Japan. Their conclusions stated that the telepresence robot helped students that do not understand the same language interact with each other like they would if they were in the class in-person, and there were significant gains in user interaction and interest over regular conferencing methods. Han (Han \& Conti, 2020) examined the attitude towards telepresence robots in the educational space by teachers. The Kubi robot was used in the experiment and 112 teachers participated. Their results showed that the teachers have a positive outlook on telepresence robots and recognize their usefulness in the educational space, despite some minor drawbacks. Liao (Liao \& Lu, 2018) explored the use of telepresence robots on foreign language learners. There were 3 participants being taught remotely by a native English speaker in a campus tour activity. They found that the robot provided a more enjoyable and authentic user experience which promotes foreign language learning. There are also other papers that discuss the use of telepresence robots ((Zhang et al., 2017); (Edwards et al., 2017); (Okamura \& Tanaka, 2016); (Newhart \& Olson, 2017); (Cha et al., 2017)).to uniform use of online forms for all classes in the final year of data collection. Table 1 summarizes the literature survey results.

Table 1: A summary of the literature survey results.

\begin{tabular}{|c|c|c|c|}
\hline Author & Robot Type & Group & Finding \\
\hline $\begin{array}{l}\text { (Saerbeck et al., } \\
\text { 2010) }\end{array}$ & Social & $\begin{array}{l}16 \text { children ages } \\
\text { between } 10-16\end{array}$ & $\begin{array}{l}\text { Students showed significant improvements in their } \\
\text { performance and were able to more likely to remember } \\
\text { what they were taught. }\end{array}$ \\
\hline $\begin{array}{l}\text { (Kandlhofer, \& } \\
\text { Steinbauer, } \\
\text { 2014) }\end{array}$ & Social & $\begin{array}{l}242 \text { children with } \\
\text { mean age of } 14 .\end{array}$ & $\begin{array}{l}\text { The children showed positive improvements in their } \\
\text { social and academic performance after being taught by } \\
\text { the robot. }\end{array}$ \\
\hline (Pop et al.,2013) & Social & $\begin{array}{l}20 \text { special needs } \\
\text { children with } \\
\text { ages between } 4 \text { - } \\
9\end{array}$ & $\begin{array}{l}\text { The social robot noticeably improved the children's } \\
\text { social interaction and they were much more likely to } \\
\text { achieve the goal of the task without further assistance. }\end{array}$ \\
\hline $\begin{array}{l}\text { (Wang, et al. } \\
\text { 2016) }\end{array}$ & Social & $\begin{array}{l}32 \text { autistic people } \\
\text { with ages } \\
\text { between } 18-60\end{array}$ & $\begin{array}{l}\text { Due to the robot's toy-like, simple nature, it was much } \\
\text { easier to teach emotional concepts using the robot rather } \\
\text { than a human instructor. The participants also showed } \\
\text { worthy development in their overall emotional skills. }\end{array}$ \\
\hline
\end{tabular}




\begin{tabular}{|c|c|c|c|}
\hline $\begin{array}{l}\text { (Chang et al., } \\
\text { 2010) }\end{array}$ & Social & $\begin{array}{l}1005^{\text {th }} \text { grade } \\
\text { children } \\
\text { acrosit } \\
\text { across } 3 \text { groups }\end{array}$ & $\begin{array}{l}\text { The robot increased engagement during the lessons and } \\
\text { the students were more likely to contribute to and learn } \\
\text { from the lessons. }\end{array}$ \\
\hline $\begin{array}{l}\text { (Kwon, } \\
\text { 2010) }\end{array}$ & Telepresence & $\begin{array}{l}\text { Children of } \\
\text { unspecified } \\
\text { numbers or age. }\end{array}$ & $\begin{array}{l}\text { While there may have been some slight problems, the } \\
\text { telepresence robot almost managed to provide a seamless, } \\
\text { in-person like experience for both the teacher and the } \\
\text { students being taught. }\end{array}$ \\
\hline $\begin{array}{l}\text { (Tanaka et al., } \\
\text { 2014) }\end{array}$ & Telepresence & $\begin{array}{l}52 \text { participants } \\
\text { aged } 4-8 \text { years } \\
\text { old }\end{array}$ & $\begin{array}{l}\text { The children were more engaged during the lessons and } \\
\text { they were less likely to freeze when asked a question they } \\
\text { did not understand. }\end{array}$ \\
\hline $\begin{array}{l}\text { (Tanaka et al., } \\
\text { 2013) }\end{array}$ & Telepresence & $\begin{array}{l}200 \text { participants } \\
\text { of unspecified } \\
\text { age group }\end{array}$ & $\begin{array}{l}\text { The telepresence robot helped students that do not } \\
\text { understand the same language interact with each other } \\
\text { like they would if they were in the class in-person, and } \\
\text { there were significant gains in user interaction and } \\
\text { interest over regular conferencing methods. }\end{array}$ \\
\hline $\begin{array}{l}\text { (Han } \& \\
\text { 2020). }\end{array}$ & Telepresence & 112 teachers & $\begin{array}{l}\text { The teachers have a positive outlook on telepresence } \\
\text { robots and recognize their usefulness in the educational } \\
\text { space, despite some minor drawbacks. }\end{array}$ \\
\hline $\begin{array}{l}\text { (Liao } \\
\text { 2018) }\end{array}$ & Telepresence & $\begin{array}{l}3 \text { participants of } \\
\text { unknown ages }\end{array}$ & $\begin{array}{l}\text { The robot provided a more enjoyable and authentic user } \\
\text { experience which promotes foreign language learning. }\end{array}$ \\
\hline
\end{tabular}

\section{Discussion}

Social robots are slowly gaining traction in the educational space. They have several different advantages that make them practical and useful tools in the classroom. The most important advantage that that they have over regular education methods are their customizability. Social robots can be fitted with all sorts of different parts, such as screens, cameras, microphones, speakers, tactile sensors and more. This can allow them to be specialized for any use case and need. Their physical appearance is also infinitely customizable, ranging from little toys/ plushies look alike to humanoid robots with robust movement and functionality. This customizability is especially useful in educating with special needs children. For example, a more toy like appearance can be implemented so as to not overload autistic children's senses, or the robot can be equipped with complex realistic hands to accurately emulate and teach sign language. Another advantage that they have is their ability to be programmed. As long as a skilled programmer is involved, it is possible to create a program that suits all needs and makes the robots do all necessary tasks. For example, the robot can be programmed to dance, play, detect and it can be programmed to communicate in a number of ways; via sign language or spoken languages such as English, French, Spanish. This program, once it is completed, tested and ready, can then be widely distributed to many other robots. Deploying several robots with the correct uploaded programs to aid the teacher is a lot faster, easier and more efficient than employing and training more teachers. Languages like sign language also have a lot less teachers than other languages, like English, so therefore it is 
sometimes harder to find a teacher to employ. While social robots can teach students on their own, they are usually most effective when they are operated alongside a human tutor.

Of course, social robots also have a few crucial disadvantages that need to be taken into account before deployment. The biggest disadvantage is currently initial cost. A fully featured NAO humanoid social robot, for example, costs 8000 dollars, which can quickly add up when multiple of them are deployed in an educational environment. Another major drawback is the need to find a prewritten program to upload to the robot that suits your needs, or to employ a skillful programmer if the task is too specific, which can also take both time and money. The final, and arguably, the biggest drawback, is the loss of jobs opportunities. Currently, it is not possible to replace teachers, but judging by how fast robotics and artificial intelligence are being developed, fully featured robot teachers could become a reality sooner rather than later.

Telepresence robots are also slowly making their way into the educational field, and they also have a slew of advantages that come with them. The most monumental advantage is having intercontinental communication and interaction between people. This is especially useful for employing foreign language teachers. This is useful for the teachers because they can have a much wider range for employment (all over the world, rather than locally) and this saves them both time and money, since they do not have to travel to the country in which they are teaching in. This can also be applied to students, who want to learn a foreign language that is not available locally or individuals that are trying to teach/learn but cannot attend due to an illness/ disability that renders them immobile. This will allow these individuals to experience an uncompromised, usually seamless in-person academic experience. Another advantage is big increase in engagement and happiness of students during the lesson over other comparable methods, like video conferencing for example. This is due to the fact that the telepresence experience feels a lot more social and authentic (one on one interactions for example), incentivizing students to work harder and remain focused in the class. With the recent pandemic that has taken over the world forcing everyone to work from home, a system like this is applicable and useful than ever before.

Unfortunately, these systems also have a few disadvantages. The primary disadvantage currently is their reliance on a stable, high speed internet connection to operate and currently, not all countries have access to infrastructures that can support a system like this. Low speed internet connections can result in a degraded experience, often in the form of high latency between actions and unintelligible low-resolution sound/video. Another disadvantage is the general clumsiness of the system, since they are usually fitted with wheels that have limited movements and are usually 
not fitted with arms for physical interactions. If these issues were resolved with better equipment, that would significantly increase the price and make these telepresence systems even less accessible to the majority of people and educational institutions.

When these two systems are compared, it can be seen that they serve different functions. The social robots are more useful for increasing engagement of students in the class, while the telepresence robots are best used to connect people all over the world together and provide them with a seamless, in-person educational experience. It can then be safely concluded that future of educational environments would actually incorporate both of these technologies to provide the best experience for as wide of a range of people as possible, wherever they are living and whatever disabilities/ challenges they are experiencing.

\section{Conclusion}

This paper aimed to compare both social robots and telepresence robots to see which one is more useful and decide which one will be incorporated in the future's educational spaces. A literature survey was performed to find other research papers that tested these types of robots in a wide range of academic environments and participants to compare the robots' usefulness and effectiveness. A comparison segment was also produced, listing all advantages and disadvantages of each type of robot and comparing them. It can then be safely concluded that the future of educational environments would incorporate both of these technologies since they serve different functions. This is to provide the best experience for as wide of a range of people as possible, wherever they are living and whatever disabilities/ challenges they are experiencing. There is a need to critically review robotics in the teaching environment and examine their impact on the student attitude, engagement, and performance in both typical and special needs students.

However, a well-defined systematic review should develop to answer significant research questions such as:

-How do robots are useful in education?

-How do teaching-based robots correlate with student performance?

-How do teaching-based robots correlate with student engagement?

\section{Acknowledgment}

The research leading to these results has received no Grant Funding.

\section{References}

[1]. Alemi, M., Meghdari, A., \& Ghazisaedy, M. (2014). Employing humanoid robots for teaching English language in Iranian junior high-schools. International Journal of Humanoid Robotics, 11(03), 1450022. 
[2]. Cha, E., Chen, S., \& Mataric, M. J. (2017). Designing telepresence robots for K-12 education. In 2017 26th IEEE International Symposium on Robot and Human Interactive Communication (RO-MAN) (pp. 683-688). IEEE.

[3]. Chang, C. W., Lee, J. H., Chao, P. Y., Wang, C. Y., \& Chen, G. D. (2010). Exploring the possibility of using humanoid robots as instructional tools for teaching a second language in primary school. Journal of Educational Technology \& Society, 13(2), 13-24.

[4]. Conti, D., Di Nuovo, A., Cirasa, C., \& Di Nuovo, S. (2017, March). A comparison of kindergarten storytelling by human and humanoid robot with different social behavior. In Proceedings of the companion of the 2017 ACM/IEEE international conference on human-robot interaction (pp. 97-98).

[5]. Edwards, A., Edwards, C., Spence, P. R., Harris, C., \& Gambino, A. (2016). Robots in the classroom: Differences in students' perceptions of credibility and learning between "teacher as robot" and "robot as teacher". Computers in Human Behavior, 65 , 627-634.

[6]. Han, J., \& Conti, D. (2020). The use of UTAUT and post acceptance models to investigate the attitude towards a telepresence robot in an educational setting. Robotics, 9(2), 34.

[7]. IFR, (2020a). https://ifr.org/ifr-press-releases/news/record-2.7-million-robots-work-in-factories-around-the-globe

[8]. 1IFR, (2020a). https://ifr.org/ifr-press-releases/news/robots-double-worldwide-by-2020.

[9]. Jamet, F., Masson, O., Jacquet, B., Stilgenbauer, J. L., \& Baratgin, J. (2018). Learning by teaching with humanoid robot: a new powerful experimental tool to improve children's learning ability. Journal of Robotics, 2018.

[10]. Kandlhofer, M. \& Steinbauer, G., (2014). Evaluating the impact of robotics in education on pupils' skills and attitudes. Proceeding of the 4th International Workshop Teaching Robotics. Teaching with Robotics \& 5th International Conference Robotics in Education, 101-9.

[11]. Kwon, O. H., Koo, S. Y., Kim, Y. G., \& Kwon, D. S. (2010, October). Telepresence robot system for English tutoring. In 2010 ieee workshop on advanced robotics and its social impacts (pp. 152-155). IEEE.

[12].Liao, J., \& Lu, X. (2018). Exploring the affordances of telepresence robots in foreign language learning. Language Learning \& Technology, 22(3), 20-32.

[13]. Mubin, O., Stevens, C. J., Shahid, S., Al Mahmud, A., \& Dong, J. J. (2013). A review of the applicability of robots in education. Journal of Technology in Education and Learning, 1(209-0015), 13.

[14]. Newhart, V. A., \& Olson, J. S. (2017, May). My student is a robot: How schools manage telepresence experiences for students. In Proceedings of the 2017 CHI conference on human factors in computing systems (pp. 342-347).

[15]. Okamura, E., \& Tanaka, F. (2016, March). A pilot study about remote teaching by elderly people to children over a two-way telepresence robot system. In 2016 11th ACM/IEEE International Conference on Human-Robot Interaction (HRI) (pp. 489490). IEEE.

[16]. Pop, C. A., Simut, R. E., Pintea, S., Saldien, J., Rusu, A. S., Vanderfaeillie, J., Vanderborght, B. J. J. o. E. C. R. (2013). Social robots vs. computer display: Does the way social stories are delivered make a difference for their effectiveness on ASD children? , 49(3), 381-401.

[17]. Saerbeck, M., Schut, T., Bartneck, C. \& Janse, M. D. (2010) Expressive robots in education: varying the degree of social supportive behavior of a robotic tutor. Proceedings of the SIGCHI conference on human factors in computing systems, 16131622.

[18]. Tanaka, F., Takahashi, T., Matsuzoe, S., Tazawa, N., \& Morita, M. (2014, March). Telepresence robot helps children in communicating with teachers who speak a different language. In Proceedings of the 2014 ACM/IEEE international conference on Human-robot interaction (pp. 399-406).

[19]. Tanaka, F., Takahashi, T., Matsuzoe, S., Tazawa, N., \& Morita, M. (2013, November). Child-operated telepresence robot: a field trial connecting classrooms between Australia and Japan. In 2013 IEEE/RSJ International Conference on Intelligent Robots and Systems (pp. 5896-5901). IEEE.

[20]. Wang, H., Hsiao, P.-Y., \& Min, B.-C. (2016). Examine the Potential of Robots to Teach Autistic Children Emotional Concepts: A Preliminary Study. Paper presented at the International Conference on Social Robotics.

[21]. You, Z. J., Shen, C. Y., Chang, C. W., Liu, B. J., \& Chen, G. D. (2006, July). A robot as a teaching assistant in an English class. In Sixth IEEE international conference on advanced learning technologies (ICALT'06) (pp. 87-91). IEEE.

[22]. Zhang, M., Duan, P., Zhang, Z., \& Esche, S. (2018). Development of telepresence teaching robots with social capabilities. In ASME 2018 International Mechanical Engineering Congress and Exposition. American Society of Mechanical Engineers Digital Collection.

(C) Author(s) and ACAA permit unrestricted use, distribution, and reproduction in any medium,
provided the original work with proper citation. This work is licensed under Creative Commons Attribution
International License (CC BY 4.0).

